\title{
ISCHAEMIC CENTRAL RETINAL VEIN OCCLUSION IN THE YOUNG
}

\author{
AMOD GUPTA ${ }^{1}$, ANITA AGARWAL $^{1}$, R. K. BANSAL ${ }^{1}$, ANUPAM AGARWAL ${ }^{2}$ and K. S. CHUGH ${ }^{2}$ \\ Chandigarh, India
}

\begin{abstract}
SUMMARY
Little is known about the behaviour of central retinal vein occlusion (CRVO) in the young. We studied the course and visual outcome in 25 patients with CRVO aged less than 40 years with special reference to the association with underlying systemic disorders. Eight patients had ischaemic CRVO while 17 had non-ischaemic CRVO. Systemic disorders associated with ischaemic CRVO included end-stage renal disease in 3 , and hypercholesterolaemia, $\beta$-thalassaemia and hypertension in 1 each. All patients with ischaemic CRVO had unusually severe disease and a rapid downhill course. Management included panretinal photocoagulation in 7 eyes, trabeculectomy with 5-fluorouracil in 3 eyes and cyclocryopexy in 2 eyes. Despite this 3 eyes became phthisical and the final visual acuity in all eyes ranged from no light perception to 6/60. Three patients with end-stage renal disease died within 15 months of diagnosis of venous occlusion.
\end{abstract}

Central retinal vein occlusion (CRVO) is seen typically in the elderly population and is often associated with hypertension, ${ }^{1}$ arteriosclerosis, ${ }^{2}$ hypercoagulable states $^{3}$ or glaucoma. ${ }^{4}$ It comprises two distinct entities: a mild nonischaemic and a severe ischaemic variety. ${ }^{5}$ In reported series up to $10 \%$ of the CRVO patients are less than 40 years of age. ${ }^{6,7}$ In the young, CRVO has been reported to be frequently mild and non-ischaemic, ${ }^{8}$ though occurrence of ischaemic CRVO is not unknown. ${ }^{9}$ This prospective study describes our observations of ischaemic CRVO in 8 patients, with special reference to its severity, course, visual outcome and the pathogenetic role of underlying systemic disorders.

\section{MATERIAL AND METHODS}

Twenty-five consecutive patients aged 40 years or less suffering from CRVO who came under our observation

Correspondence to: Dr Amod Gupta, Department of Ophthalmology, Postgraduate Institute of Medical Education and Research, Chandigarh-160 012, India. between 1988 and 1991 were included in this study. A complete ocular examination including best corrected visual acuity, pupil reaction, intraocular pressure, biomicroscopy and fundoscopy. Fundus fluorescein angiography was done in all patients at presentation and at subsequent follow-up visits.

Clinical evaluation included a detailed history and physical examination for the presence or absence of possible aetiological factors such as hypertension, smoking, diabetes mellitus and use of oral contraceptives. Investigations included routine blood chemistry, lipid profile, haemogram, chest radiograph and electrocardiogram.

We defined CRVO as venous dilatation and tortuosity associated with retinal haemorrhages scattered up to the periphery in all the four quadrants, with or without cotton wool spots and/or optic disc oedema. CRVO was classified as ischaemic if any of the following events occurred at any time during the course of the disease: $:^{10,11}$

1. Relative afferent pupillary defect and decrease of visual acuity to $\leqslant 3 / 60$.

2. Severe degree of retinal ischaemia on fundus fluorescein angiography.

3. Ocular neovascularisation: iris and/or retinal new vessel formation.

All other cases were classified as non-ischaemic CRVO.

\section{RESULTS}

Of the 25 patients (29 eyes) studied, 8 (9 eyes) had ischaemic CRVO while 17 (20 eyes) had non-ischaemic CRVO. Of the 8 patients with ischaemic CRVO, 5 were male and 3 female in the age range $24-40$ years. Follow-up of ischaemic CRVO varied from 3 to 18 months (mean 9.4). Six of 8 patients (75\%) with ischaemic CRVO had associated known risk factors (Table I). These were end-stage renal disease in 3 and hypercholesterolaemia (serum cholesterol $500 \mathrm{mg} \%$ ), essential hypertension (diastolic blood pressure between 110 and $120 \mathrm{mmHg}$ ) and $\beta$-thalassaemia with pregnancy in 1 patient each. 
Table I. Central retinal vein occlusion associated with systemic disorders

\begin{tabular}{llll}
\hline $\begin{array}{l}\text { Ischaemic } \\
(n=8)\end{array}$ & & $\begin{array}{l}\text { Non-ischaemic } \\
(n=17)\end{array}$ \\
\hline End-stage renal disease & 3 & Bronchial asthma & 1 \\
Hypercholesterolaemia & 1 & Mild hypertension & 1 \\
Hypertension & 1 & Sarcoidosis & 1 \\
$\beta$-Thalassaemia & 1 & Pregnancy/DLE & 1 \\
& & Diabetes mellitus & 1 \\
& & Pituitary tumour & 1 \\
\hline
\end{tabular}

DLE, discoid lupus erythematosus.

\section{Clinical Course}

The clinical course of the 8 patients with ischaemic CRVO is summarised in Table II. Two illustrative patients are described.

Case 3. A 27-year-old woman was found to be suffering from idiopathic diffuse crescentic glomerulonephritis in February 1990 and was started on a biweekly maintenance haemodialysis programme. In December 1990 blood pressure was $180 / 120 \mathrm{mmHg}$ and she complained of rapid diminution of vision in both eyes. Visual acuity was $6 / 36$ in the right eye and $6 / 18$ in the left. Anterior segment examination was unremarkable. Fundus examination revealed bilateral optic disc oedema, multiple cotton wool spots, macular star and acute Elschnig's spots, suggestive of bilateral malignant hypertensive retinopathy and choroidopathy. Following 4 weeks of antihypertensive therapy the ocular signs resolved and visual acuity improved to $6 / 6$ in each eye. In February 1991 she developed sudden diminution of vision in her left eye. The visual acuity was $6 / 6$ in the right eye and limited to counting fingers at $1 / 3$ metre in the left eye. Examination revealed a left afferent pupillary defect. On fundoscopy, massive oedema of optic disc and macula, multiple cotton wool spots and large ret- inal haemorrhages were seen in all four quadrants (Fig. 1). On fluorescein angiography there was venous stasis and multiple areas of capillary non-perfusion (Fig. 2). Visual fields of the left eye showed peripheral constriction and a large central scotoma. The changes were consistent with ischaemic CRVO of the left eye. The patient underwent prophylactic krypton red panretinal photocoagulation (PRP) and was followed regularly at 2-weekly intervals. Six months later she developed retinal neovascularisation elsewhere (NVE) with a preretinal bleed (Fig. 3). At this stage she was detected to be positive for antibodies to human immunodeficiency virus (HIV) while on maintenance haemodialysis, and died a month later.

Case 6. A 26-year-old man suffering from membranoproliferative glomerulonephritis and end-stage renal failure underwent a live unrelated renal transplant on 17 February 1990, and was receiving immunosuppressive therapy. In March 1990 he developed leucopenia, oesophageal candidiasis and mild hypertension followed by sudden loss of vision in the right eye. Visual acuity was reduced to light perception in the right eye and was $6 / 6$ in the left. An afferent pupillary defect was present in the right eye. On fundoscopy the optic disc was swollen with multiple confluent cotton wool spots on and around the optic disc and posterior pole. The veins were engorged and 'box-carring' of the venous column was evident (Fig. 4). On fundus fluorescein angiography the arterioles were attenuated with delayed filling of a few veins (Figs. 5 and $6)$.

Four weeks later he developed new vessels on the optic disc (NVD). While awaiting panretinal photocoagulation he developed severe neovascular glaucoma (NVG; intraocular pressure $70 \mathrm{mmHg}$ ) in the right eye within 6 weeks of venous occlusion. Medical control of glaucoma allowed sufficient clarity of the media to carry out a full-

Table II. Clinical characteristics of patients with ischaemic central retinal vein occlusion

\begin{tabular}{|c|c|c|c|c|c|c|c|c|c|c|c|}
\hline \multirow{2}{*}{$\begin{array}{l}\text { Case } \\
\text { no. }\end{array}$} & \multirow{2}{*}{$\begin{array}{l}\text { Age/ } \\
\text { sex }\end{array}$} & \multirow{2}{*}{$\begin{array}{l}\text { Interval } \\
\text { from onset }\end{array}$} & \multirow[b]{2}{*}{ Eye } & \multicolumn{2}{|c|}{ Visual acuity } & \multirow{2}{*}{$\begin{array}{l}\text { Ocular } \\
\text { complications }\end{array}$} & \multirow[b]{2}{*}{ Treatment } & \multirow{2}{*}{$\begin{array}{l}\text { Systemic } \\
\text { disease }\end{array}$} & \multirow[b]{2}{*}{ Investigations } & \multirow{2}{*}{$\begin{array}{l}\text { Final } \\
\text { outcome }\end{array}$} & \multirow{2}{*}{$\begin{array}{l}\text { Follow-ur } \\
\text { (months) }\end{array}$} \\
\hline & & & & Initial & Final & & & & & & \\
\hline 1 & $31 \mathrm{M}$ & 3 days & OS & $\mathrm{CF}$ & $6 / 60$ & NVD/NVE & PRP & $\begin{array}{l}\text { ESRD } \\
\text { Renal T. }\end{array}$ & $\begin{array}{l}\text { BU } 140 \mathrm{mg} \% \\
\text { SCr. } 8.4 \mathrm{mg} \% \\
\mathrm{Hb} 8.0 \mathrm{mg} \%\end{array}$ & $\begin{array}{l}\text { NV reg. } \\
\text { Died }\end{array}$ & 12 \\
\hline 2 & $35 \mathrm{M}$ & $2 \mathrm{mo}$ & $\mathrm{OU}$ & $\begin{array}{l}6 / 9 \\
\mathrm{LP}\end{array}$ & $\begin{array}{l}6 / 60 \\
\mathrm{LP}\end{array}$ & $\begin{array}{l}\text { NVD, NVE, NVG } \\
\text { NVG, Vit. haem. }\end{array}$ & $\begin{array}{l}\text { PRP, Trab. } \\
\text { Cyclo-cryo }\end{array}$ & HT & Idiopathic & $\begin{array}{l}\text { NV reg. } \\
\text { Gl. cont. } \\
\text { Phthisis }\end{array}$ & 3 \\
\hline 3 & $27 \mathrm{~F}$ & 7 days & OS & $\mathrm{CF}$ & $\mathrm{CF}$ & NVE & PRP & ESRD & $\begin{array}{l}\text { BU } 140 \mathrm{mg} \% \\
\text { SCr. } 6.4 \mathrm{mg} \% \\
\text { ESR } 70 \mathrm{~mm} \\
\text { HIV+ve }\end{array}$ & Died & 10 \\
\hline 4 & $24 \mathrm{~F}$ & $1 \mathrm{mo}$ & OD & $\mathrm{CF}$ & LP & NVD & PRP & $\begin{array}{l}\beta \text {-thal. } \\
\text { Pregnancy }\end{array}$ & $\mathrm{Hb} 3.8 \mathrm{gm} \%$ & NV reg. & 8 \\
\hline 5 & $40 \mathrm{M}$ & $1 \mathrm{mo}$ & OD & $6 / 60$ & $\mathrm{CF}$ & NVD, NVE & PRP & $\mathrm{Nil}$ & - & NV reg. & 3 \\
\hline 6 & $26 \mathrm{M}$ & 1 day & $\mathrm{OD}$ & LP & LP & NVD, NVG & PRP & $\begin{array}{l}\text { ESRD } \\
\text { Renal T. }\end{array}$ & $\begin{array}{l}\text { Renal F normal } \\
\text { ESR } 70 \mathrm{~mm} \\
\text { HIV-ve }\end{array}$ & $\begin{array}{l}\text { NV reg. } \\
\text { Phthisis } \\
\text { Died }\end{array}$ & 15 \\
\hline 7 & $38 \mathrm{M}$ & 1 day & OS & $\mathrm{CF}$ & NLP & NVG & Cyclo-cryo & Hyperchol. & SChol. $500 \mathrm{mg} \%$ & Phthisis & 18 \\
\hline 8 & $40 \mathrm{~F}$ & $2 \mathrm{mo}$ & OD & NLP & NLP & NVG & $\begin{array}{l}\text { PRP, ARC } \\
\text { Trab. }\end{array}$ & Nil. & - & $\begin{array}{l}\text { NV reg. } \\
\text { G.l. cont. }\end{array}$ & 6 \\
\hline
\end{tabular}

mo., month; OD, right eye; OS, left eye; OU, both eyes; $\mathrm{CF}$, counting fingers; LP, light perception; NLP, no light perception; NVD, neovascularisation on optic disc; NVE, neovascularisation elsewhere; NVG, neovascular glaucoma; PRP, panretinal photocoagulation; Trab., trabeculectomy with 5-fluorouracil; ARC, anterior retinal cryopexy; ESRD, end-stage renal disease; T, transplant; HT, hypertension; $\beta$-thal, $\beta$-thalassaemia; Hyperchol, hypercholesterolaemia; BU, blood urea; SCr., serum creatinine; Hb, haemoglobin; ESR, erythrocyte sedimentation rate; HIV, human immunodeficiency virus; SChol., serum cholesterol; NV reg, regression of neovessels; Gl. cont., glaucoma controlled. 


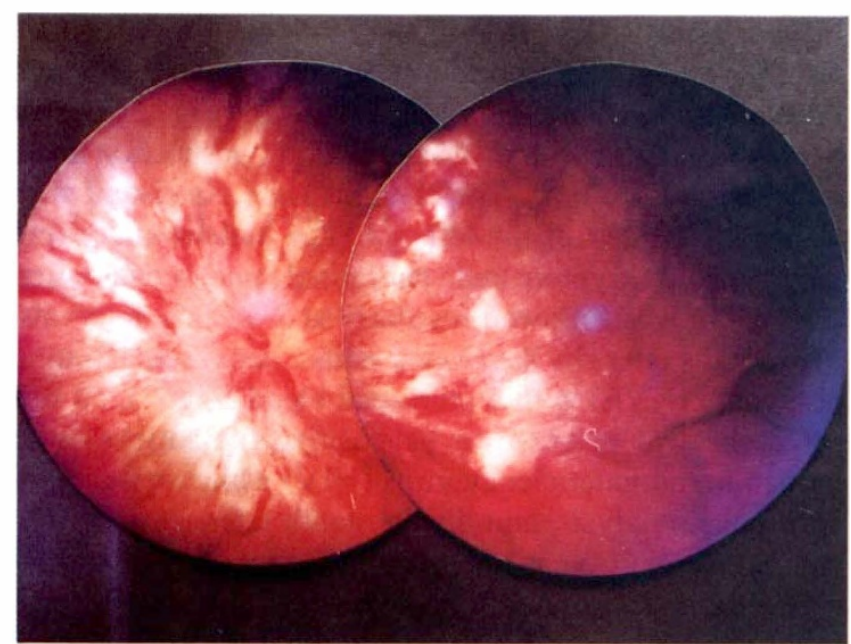

Fig. 1. Case 3: Fundus photograph of the left eye showing massive optic disc oedema, multiple cotton wool spots and haemorrhages.

scale krypton laser PRP. He required trabeculectomy with adjuvant 5-fluorouracil (total dose $10 \times 5 \mathrm{mg}$ ) for control of glaucoma. The eye, however, became hypotonic, resulting in phthisis bulbi over the next 6 months. He died from disseminated fungal infection in July 1991 despite antifungal therapy.

\section{Ocular Complications and Management}

All the 9 affected eyes of the 8 patients developed ocular neovascularisation 1-6 months after the onset of vascular occlusion: NVD/NVE alone in 4 eyes, NVG alone in 2 eyes, and NVD/NVE with NVG in 3 eyes. Krypton laser panretinal photocoagulation was done in 7 eyes either prophylactically (case 3 ) or at the time of detecting ocular neovascularisation, and caused regression in all the treated eyes except in case 3 . One eye (case 8 ) required anterior

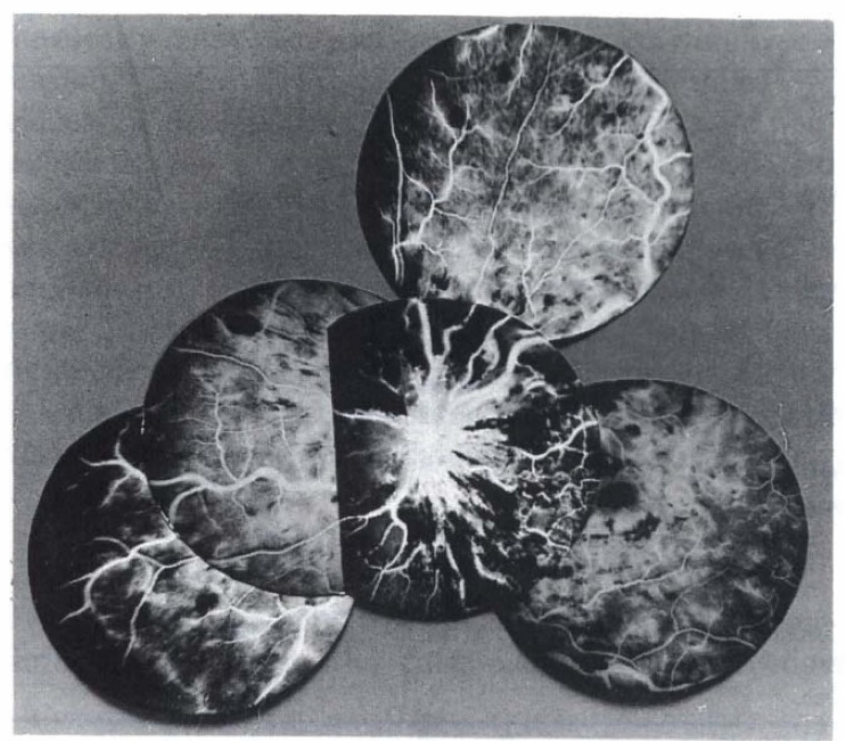

Fig. 2. Case 3: Composite fundus fluorescein angiogram showing disc oedema, venous dilatation, macular oedema, blocked fluorescence and venous leakage. retinal cryopexy in addition. Of the 4 eyes with only NVD/ NVE, complete regression of neovessels occurred with laser scatter alone in 3 eyes. Of the 5 eyes with NVG, trabeculectomy with adjuvant 5 -fluorouracil was performed in 3 eyes after achieving control of ocular neovascularisation. In 2 eyes (cases 2 right eye and 8) glaucoma was controlled and 1 eye (case 6) ended in phthisis bulbi. Two eyes (cases 2 left eye and 7) subjected to cyclocryopexy alone developed phthisis bulbi. Finally, the ocular neovascularisation could be controlled in 5 eyes with visual acuity varying from no light perception to 6/60. All 3 patients with end-stage renal disease died within 10-15 months of the onset of vascular occlusion.

\section{DISCUSSION}

Central retinal vein occlusion is considered a disease of the elderly, with more than $90 \%$ of cases occurring in patients over 50 years of age. ${ }^{4}$ The condition is often associated with systemic vascular disease and more than half of patients suffer from hypertension and one-third from diabetes mellitus and atheroslcerotic heart disease.,12 Other causes of CRVO include abnormalities in the vessel wall and alterations in the clotting mechanisms and blood viscosity. ${ }^{3.4}$ Since the majority of the patients who have been observed are in the older age group, the disease pattern in the younger subjects has not been highlighted. Review of the literature has revealed only a few patients with CRVO under the age of 40 years. ${ }^{6,89}$ Walters and Spalton $^{8}$ found only 21 of 182 patients with CRVO younger than 40 years of age. Detailed review of 17 of these patients revealed that all of them suffered from nonischaemic CRVO with a benign course and a good visual outcome. None of them had any associated systemic disease. These authors concluded that CRVO in the young is probably a different disease from that seen in the elderly

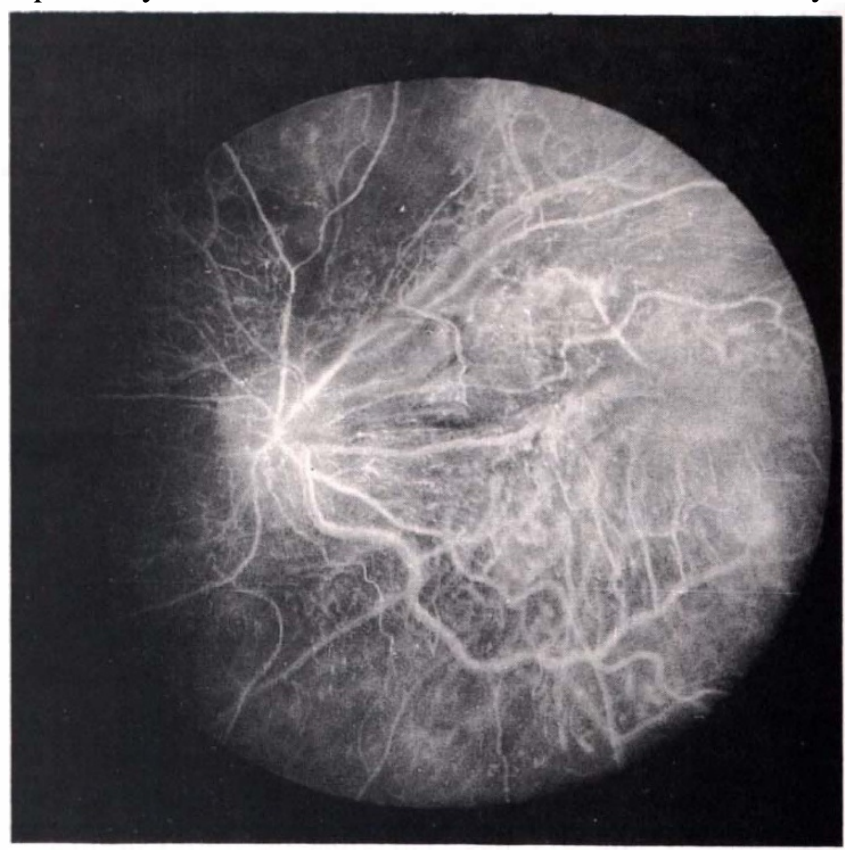

Fig. 3. Case 3: Fundus fluorescein angiogram of the left eye 6 months later showing extensive neovascularisation temporal to the optic disc. 


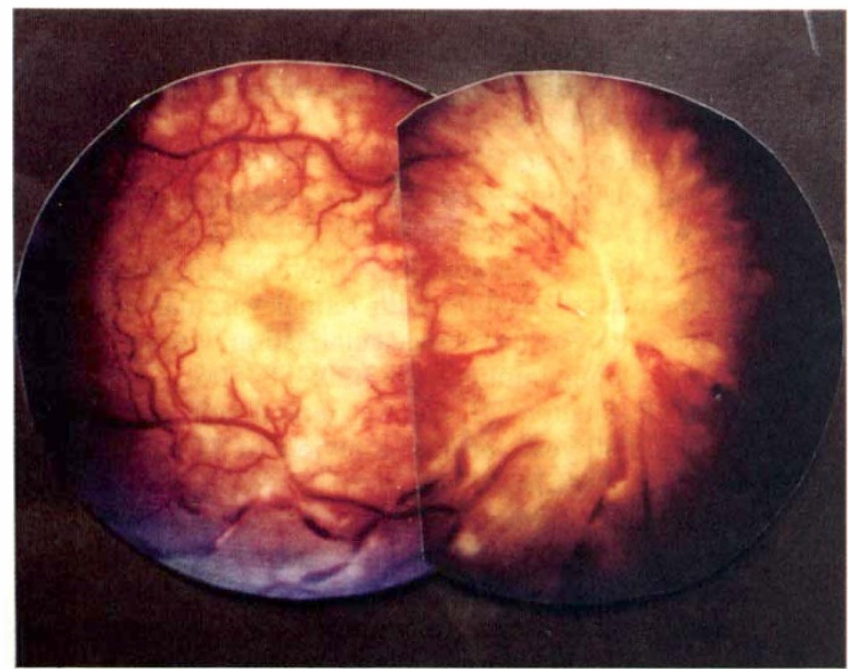

Fig. 4. Case 6: Fundus photograph of the right eve showing confluent cotton wool spots, venous dilatation. 'box-carring' and retinal haemorrhages.

because of its unilaterality and excellent visual prognosis. In contrast, Priluck et al." observed complete CRVO in half of their 42 patients aged 40 years or less. Eight of these $42(14 \%)$ had a recognised systemic disorder at the time of initial ocular diagnosis, which was incomplete CRVO in 3 and complete CRVO in 5 . There was no significant difference in the incidence of systemic disorders between the two groups.

In the present study 8 of 25 patients suffered from ischaemic CRVO and 6 of these $8(75 \%)$ had an associated systemic disorder. All 3 patients with renal disease had secondary hypertension with diastolic blood pressure varying between 12() and $130 \mathrm{mmHg}$. Retinal vein occlusion in these patients could have involved a complex inter-

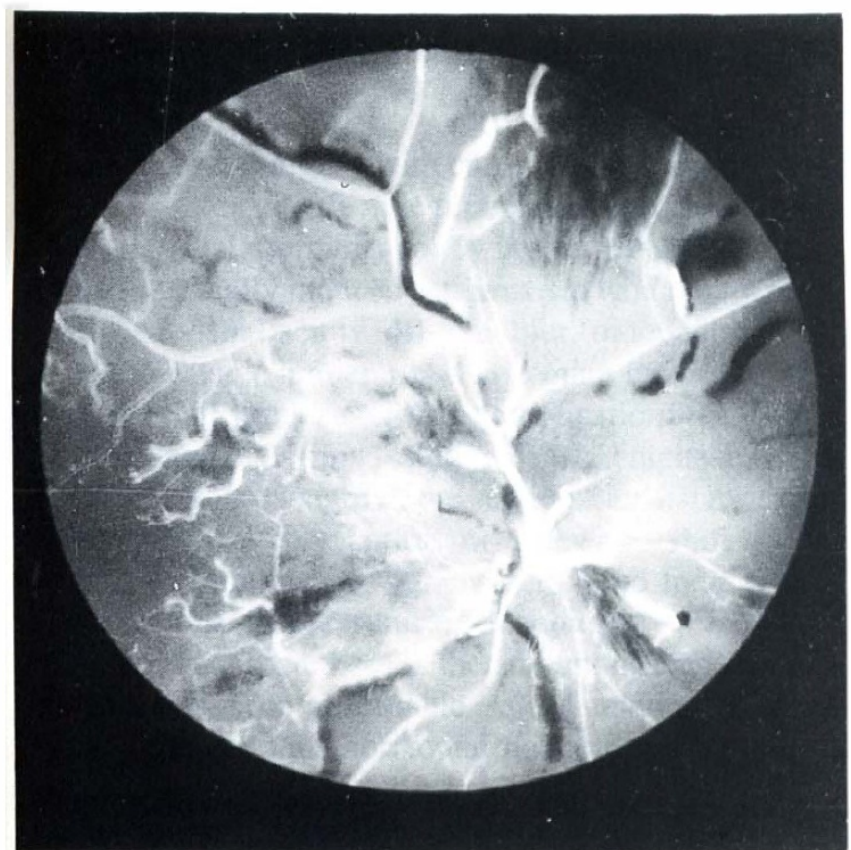

Fig. 5. Case 6: Early phase fundus Huorescein angiogram showing non-perfusion of the optic disc. attemuated arterioles and large areas of capillary non-perfission. action between multiple factors affecting vessel wall as well as blood. Hypercholesterolaemia, a known risk factor in CRVO. was present in I patient who was otherwise healthy. and $\beta$-thalassaemia was found in a pregnant woman. Both of these conditions can cause changes in the blood viscosity resulting in venous occlusion. ${ }^{13}$ Frucht $e t$ al." documented ischaemic CRVO in 7 of 11 young adults. All of them had poor visual acuity and 4 had a systemic disorder at the onset. The visual acuity in 6 of 7 patients with ischaemic CRVO was less than 3/60) at onset and remained so until the last follow-up. Though a significant association was observed between ischaemic CRVO and systemic disorder, the severity of the systemic disease was not highlighted by the authors."

The most significant finding in our study was the rapid evolution of the ocular disorder in the ischaemic group. The initial visual acuity in 7 eyes was limited to counting fingers or worse. Improvement in visual acuity was seen in only $I$ of the eyes and the final acuity ranged from no light perception to 6/6(). Fundus examination in all the patients showed haemorrhages and multiple cotton wool spots at the time of presentation. All of them showed a rapid downhill course. with severe retinal ischaemia evident on fluorescein angiography.

The efficacy of prophylactic PRP in preventing NVG following ischaemic CRVO has been well documented. ${ }^{1.15}$ In the present study ocular neovessels regressed in 6 eyes subjected to krypton laser PRP and NVG was successfully prevented in 4 eyes. Despite energetic management with a combination of medical treatment. PRP and trabeculectomy with 5-fluorouracil in 3 eyes and cyclocryopexy in 2 eyes. 3 of the 5 eyes with NVG became phthisical. No previous study has documented the response of eyes of young patients with ischaemic CRVO to PRP. Since all our patients showed a

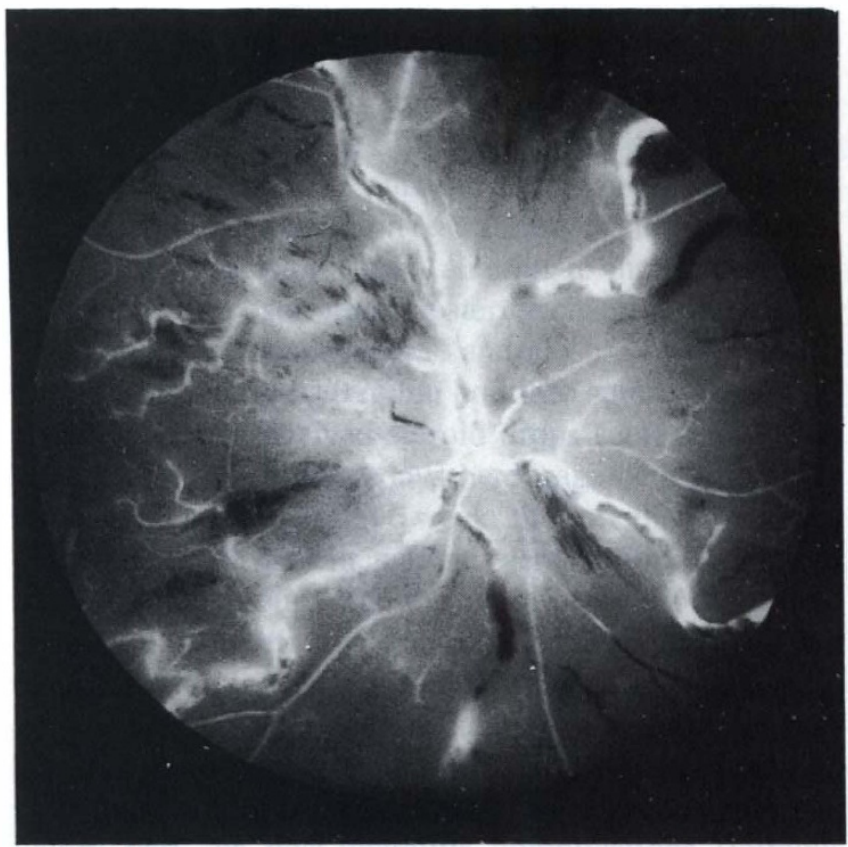

Fig. 6. Case o: Late-phase fundus fluorescein angiogram showing delaved filling of only the large veins with staining of

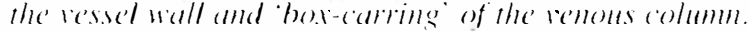


rapid progression, we suggest early prophylactic PRP in young patients with an underlying serious systemic disorder. In the series by Priluck et al., 3 of 24 eyes with complete CRVO developed NVG necessitating enucleation. Visual acuity improved in 9 eyes, while 7 eyes showed no change. Three patients with incomplete CRVO and 2 with complete CRVO died during follow-up. The time between the diagnosis of venous occlusion and death ranged from 9 to 23 years with a mean of 15 years. In contrast, 3 of our patients died within 15 months of ocular diagnosis, because of the serious nature of the underlying systemic disorder.

Our findings disprove the popular belief that CRVO in the young is mostly mild and has a universally good prognosis. One-third of our patients suffered severe ischaemic CRVO and had a rapid downhill course with poor visual outcome. Prognosis was grave in patients with CRVO associated with end-stage renal disease. Early and effective management is mandatory to prevent serious ocular and life-threatening complications.

Key words: Central retinal vein occlusion, End-stage renal disease, 5-Fluorouracil, Panretinal photocoagulation, Trabeculectomy.

\section{REFERENCES}

1. Paton A, Rubinstein K, Smith VH. Arterial insufficiency in retinal venous occlusion. Trans Ophthalmol Soc UK 1964; 84:559-86.

2. Cassady JV. Central retinal vein thrombosis. Am J Ophthalmol 1953;36:331-5.

3. Priluck IA. Impending central retinal vein occlusion associated with increased platelet aggregability. Ann Ophthalmol 1979;11:79-84.
4. Gutman FA. Evaluation of a patient with central retinal vein occlusion. Ophthalmology 1983;90:481-3.

5 . Hayreh SS. Classification of retinal vein occlusion. Ophthalmology 1983;90:458-74.

6. Priluck IA, Robertson DM, Hollenhorst RW. Long-term follow-up of occlusion of the central retinal vein in young adults. Am J Ophthalmol 1980;90:190-202.

7. Hayreh SS, Rojas P, Podhajsky P, Montague P, Woolson RF. Ocular neovascularisation with retinal vascular occlusion. III. Incidence of ocular neovascularisation with retinal vein occlusion. Ophthalmology 1983;90:488-506.

8. Walters RF, Spalton DJ. Central retinal vein occlusion in people aged 40 years or less: a review of 17 patients. Br J Ophthalmol 1990;74:30-5.

9. Frucht J, Yanko L, Merin S. Central retinal vein occlusion in young adults. Acta Ophthalmol (Copenh) 1984;62:780-6.

10. Hayreh SS, Klugman MR, Beri M, Kimura AE, Podhajsky P. Differentiation of ischemic from non-ischemic central retinal vein occlusion during the early acute phase. Graefes Arch Clin Exp Ophthalmol 1990;228:201-17.

11. Sowais GE, Thompson HS, Hayreh SS. Relative afferent pupillary defect in central retinal vein occlusion. Ophthalmology 1986;93:301-3.

12. Zegarra H, Gutman FA, Conforto J. The natural course of central retinal vein occlusion. Ophthalmology 1979;86: 1931-9.

13. McGrath MA, Wechsler F, Hunyor AB, Penny R. Systemic factors contributory to retinal vein occlusion. Arch Intern Med 1978;138:216-20.

14. Magargal LE, Brown GC, Augsburger JJ, Donoso LA. Efficacy of photocoagulation in preventing neovascular glaucoma following ischemic central retinal vein obstruction. Ophthalmology 1982;89:780-4.

15. Magargal LE, Donoso LA, Sanborn GE. Retinal ischemia and risk of neovascularisation following central retinal vein obstruction. Ophthalmology 1982;89:1241-5. 